\title{
A FEMME FATALE COMO DUPLO EM GASTÃO CRULS
}

\section{ANA RESENDE*}

Universidade do Estado do Rio de Janeiro (Uerj), Programa de Pós-Graduação em Letras (PPGL), Rio de Janeiro, RJ, Brasil.

Recebido em: 22 jan. 2021. Aprovado em: 4 mar. 2021.

Como citar este artigo: RESENDE, A. A femme fatale como duplo em Gastão Cruls. Cadernos de Pós-Graduação em Letras, v. 21, n. 1, p. 58-72, jan./abr. 2021. doi: 10.5935/cadernosletras.v21n1p58-72

\section{Resumo}

O presente artigo procura mostrar como Gastão Cruls faz uso das “imagens obsedantes [images obsédantes]" da prosa de ficção decadentista para criar uma narrativa fantástica acerca da duplicidade. Ao mesmo tempo, objetiva expor como Gastão Cruls, ao recorrer a essas “imagens obsedantes”, no romance Elza e Helena (1927) e no conto "O espelho" (1938), filia-se à tradição literária de autores como Edgar Allan Poe e Robert Louis Stevenson.

\section{Palavras-chave}

Gastão Cruls. Duplo. Femme fatale.

* E-mail: hoelterlein@gmail.com

(D) https://orcid.org/0000-0002-1294-0740 


\section{GASTÃO CRULS: DECADENTISMO E FANTÁSTICO}

No artigo "Literatura fantástica e o Modernismo” (1979), Cecília de Lara constatava uma tendência dos estudos literários de então, que consideravam a presença do fantástico sem uma tradição própria na literatura brasileira. Para Lara (1979, p. 10), essa situação caracterizaria, na verdade, um desconhecimento de produções literárias mais antigas, seja por dificuldades de acesso a fontes primárias, seja por um privilégio, a partir do fim dos anos 1920, da ficção de caráter documental e regionalista, que "monopolizou por muito tempo a atenção dos leitores e da crítica, a ponto de deixar na sombra certas produções em que o universo interior do homem se afirma como tônica". O monopólio temático evidenciava a marginalização das obras que, segundo a autora, realizavam "sondagens mais profundas no ser humano" e buscavam o "inusitado, por caminhos diversos", sob a forma de uma ruptura com o "universo linear, organizado logicamente” (LARA, 1979, p. 10).

No caso da prosa de ficção decadentista - caracterizada por uma interioridade muitas vezes neurótica e pela ênfase em fantasias, sonhos e visões -, esse descaso da crítica fica mais evidente. Por isso não admira que, ainda hoje, a produção literária decadentista brasileira seja pouco explorada, mesmo com um corpus significativo de obras. Como a ficção decadentista está associada "a muitas ideias, atitudes, orientações, movimentos, histórias, artes [e] artistas diferentes" (WEIR, 2017, p. 219), ${ }^{1}$ ela é sempre vista como uma "época de transição", na melhor das hipóteses.

Num levantamento inicial, verifiquei que, além do romance Elza e Helena, metade dos textos publicados nas coletâneas de contos de Cruls (1951), compiladas sob o título Contos reunidos, inclui temas fantásticos. Parto, portanto, da hipótese apresentada por Catherine Rancy (1982) para mostrar que o encontro entre o Decadentismo e o fantástico ${ }^{2}$ produziu formulações muito específicas da "atitude mental" (JOUVE, 1989, p. 13) finissecular, da qual encontramos vestígios na obra literária de Gastão Cruls. ${ }^{3}$

1 A tradução dos textos em língua estrangeira citados no artigo foi feita por mim, salvo quando o nome do tradutor for indicado nas referências bibliográficas.

2 Uso "fantástico" aqui no sentido de "algo que escapa às leis naturais" e, a exemplo de Catherine Rancy (1982) e Remo Ceserani (2006), considero-o como um modo ficcional trans-histórico (cf. também RUDDICK, 2007, p. 189-190). A expressão “fantástico decadentista” diz respeito, portanto, a um submodo específico do fantástico, associado à poética decadentista.

3 Gastão Cruls nasceu no Rio de Janeiro, em 1888, e faleceu na mesma cidade, em 1959. Em 1905, ingressou na Faculdade de Medicina do Rio de Janeiro. Em 1926, Cruls passou oito meses na Europa, 
Em suas narrativas, é possível constatar que há uma "concepção da vida [que não é] rígida nem mecânica” (BARRETO, 2017, p. 254) e que as angústias e os temores cotidianos que afligem o homem são veiculados por meio do fantástico. Essa visão está presente em contos como "Meu sósia”, "O espelho”, "G.C.P.A.", "O noturno no 13", entre outros.

Essa atitude mental - definida lapidarmente por Regenia Gagnier (2004, p. 36): "os nervos, mais do que os sentidos [...], caracterizaram o Decadentismo" - também está presente em Edgar Allan Poe, a quem Cruls gostava de se comparar. Segundo Fred Botting (1996, p. 78), "as distorções da imaginação" encontram um meio privilegiado "nas histórias macabras [e] alucinatórias" do autor estadunidense. Embora seus contos fossem considerados "literatura popular”, com todas as implicações negativas muitas vezes associadas ao termo, os escritores, desde o fim do século XIX, foram atraídos pela obra de Poe justamente por sua reivindicação das narrativas curtas e da busca pela "unidade de efeito”, além dos temas mórbidos. Como observa Regenia Gagnier (2004, p. 20), Poe “elevou doença, perversidade e declínio a novos cumes da expressão artística”.

\section{O FEMININNO EMI EDGAR ALLAN POE}

A presença do feminino constitui um dos temas favoritos da obra de Poe, incluindo seus poemas, contos e ensaios e, em particular, o célebre artigo sobre a poesia moderna, "A filosofia da composição", publicado na Graham's Magazine, no qual o autor conclui que o tema mais poético é "a morte de uma bela mulher” (POE, 1846, p. 164). E acrescenta, em seguida, que os lábios mais adequados a recitar um tal tema são os do "amante enlutado". Essa temática está presente em seus poemas, mas também se estende aos contos, como "Eleonora”, "Morella”, "Ligeia”, “A queda do solar de Usher" e "O retrato oval”, escritos nas décadas de 1830 e 1840.

Se, por um lado, a característica determinante das personagens femininas dos contos de Poe é estarem mortas ou muito próximas da morte, as persona-

viajando pelo continente. A essa primeira e única viagem ao exterior, ele atribuiu o seu "desaprendizado da Medicina” (SENNA, 1959, p. 8), e, ao retornar ao Brasil, abandonou a profissão para dedicar-se à literatura. Em 1928, durante cinco meses, acompanhou o general Cândido Rondon em uma expedição pela selva amazônica. O livro A Amazônia que eu vi (1930) se baseia no diário de viagem de seu autor. Entre suas coletâneas de contos e romances, estão Coivara (1920), Ao embalo da rede (1923), A Amazônia misteriosa (1925), Elza e Helena (1927). De pai a filho (1954) é seu último romance. 
gens masculinas, por outro, constituiriam "uma única sensibilidade, uma só personagem" - são homens de "temperamento nervoso; capazes de amor, lealdade e tristeza imensos, [e] de 'grande excitação' (uma expressão recorrente)” (OLIVER, 2016, p. 66). A doença mental sempre está presente, como uma desculpa para o comportamento dos personagens, pois “[suas] ações [...] costumam ser reconhecidamente insanas” (OLIVER, 2016, p. 68).

Na obra de Poe, no entanto, a temática sexual não aparece explicitada; não por acaso, em um dos primeiros estudos críticos sobre a obra do autor, Marie Bonaparte (1949, p. 210) observou que, em seus contos, os personagens masculinos não agiriam como amantes, mas como adoradores, "que não ousa[m] aproximar-se de seu objeto de adoração, pois sente[m] que ele está envolto em algum mistério perigoso e terrível". Vale observar que a psicanalista concluiu, em sua leitura dos contos, que Poe seria sexualmente impotente. $\mathrm{Na}$ apresentação à segunda parte da obra, intitulada "Tales of the mother", Marie Bonaparte (1949, p. 209-210) cita a conhecida passagem do prefácio de Charles Baudelaire sobre "as mulheres sobrenaturais” de Poe:

"Não há amor nos contos de Poe." O que corrobora a ideia da sra. Frances Osgood em relação ao respeito cavalheiresco de Poe pelas mulheres é o fato de que, apesar de seu prodigioso talento para o grotesco e para o horrível, não há, em toda a sua obra, uma única passagem associada à lubricidade ou mesmo aos prazeres sensuais. Seus retratos femininos são, por assim dizer, aureolados, brilham em meio ao vapor sobrenatural e são pintados do modo enfático de um adorador.

O fato de que o "mistério perigoso e terrível" das personagens femininas dos contos de Poe é a combinação de beleza e morte caracteriza, como já mencionado, boa parte de sua produção literária. Como observa Julian Symons (1978, p. 205), “belas mulheres têm pouca chance de sobrevivência em Poe. Frequentemente elas são consideradas vítimas dos homens e causa de destruição". As personagens femininas são representadas ora na forma da mulher frágil e frequentemente perseguida, a damsel in distress, ora na forma da femme fatale, a mulher sensual e transgressora, capaz de causar a degradação moral ou física do sexo masculino. A partir dos estudos de Mario Praz e Camille Paglia, Júlio França e Daniel Augusto P. Silva (2015, p. 51) abordam essa dicotomia, no artigo "De perseguidas a fatais: personagens femininas, sexo e horror na literatura do medo brasileira", e observam que: 
Desde a literatura gótica no século XVIII, a mulher é retratada em situações associadas à morte e ao medo. Nessas histórias, é recorrente o tópos da damsel in distress, isto é, a presença de uma personagem feminina que é vítima dos mais diversos tipos de violência, física e/ou psicológica. Já no século XIX, as representações da mulher na literatura se tornam mais diversificadas. [...] ganha força a femme fatale, e o sexo é encarado como conflito entre alma e corpo.

\section{ELZA E HELENA}

Gastão Cruls também se vale dessa temática, no início do século XX, como demonstram Júlio França e Daniel Augusto P. Silva (2015, p. 64-65) ao tratarem do conto "Noites brancas". Foi Lima Barreto (2017, p. 256), em sua resenha da coletânea de contos Coivara, quem resumiu à perfeição o impacto causado pelo conto: “Noites brancas', por exemplo, é conto fora dos nossos moldes, terrível, fantástico e doloroso. Beijos de uma morfética, dentro da noite escura. Oh! Que horror!”. Essas personagens femininas arquetípicas também foram tematizadas no romance Elza e Helena.

As resenhas acerca das primeiras obras de Cruls foram muito positivas, e não sem razão; seu autor, então com 32 anos, foi comparado a nomes como Edgar Allan Poe, Guy de Maupassant e Oscar Wilde. Poucos anos antes da publicação dos livros, ainda escrevendo sob o pseudônimo de "Sérgio Espínola", ele publicara alguns contos, como "G.C.P.A.” e "A noiva de Oscar Wilde", na Revista do Brasil, mantendo frequente troca de cartas com o então diretor da publicação, Monteiro Lobato, a quem se dizia grato por evitar a publicação da produção literária "lacrimogênea” da juventude (cf. SENNA, 1959, p. 8).

Já nessa época, o autor revelava sua preferência pelo que chamaria mais tarde, em entrevista a Homero Senna (1959), de “temas mórbidos”. Por ocasião da conversa com Senna $(1959$, p. 8), Cruls acrescenta que sua predileção não era apenas um interesse originado pela antiga profissão de médico, já que “inúmeros escritores que não foram médicos [...] também gost[avam] desses temas”. Cruls costumava enfatizar, dessa forma, a influência de autores estrangeiros comumente associados à prosa de ficção decadentista, mas também de autores brasileiros, entre os quais se destacam Carlos de Vasconcelos, Jarbas Andréa, Raul de Polillo (cf. BROCA, 1991, p. 368-371). A esses autores, Brito Broca (1991), em seu Naturalistas, parnasianos e decadistas: vida literária do Realismo ao Pré-modernismo, associa a corrente "decadente e mór- 
bida” (p. 368), caracterizada por uma "mistura de Poe, Wilde e Jean Lorrain" (p. 370).

Embora Gastão Cruls tenha tido uma carreira literária que se estendeu por mais de três décadas, participando de empreendimentos importantes com o crítico Agripino Grieco ${ }^{4}$, sua obra literária recebeu comparativamente pouca atenção.

O "Prefácio" a Elza e Helena, assinado por G. C., relata como um amigo, notável psiquiatra, a quem ele devia a iniciação na psicanálise sob a perspectiva de Príapo, apresentou-lhe uma boneca de flanela puída, já "apodrecida e mofada" (CRULS, 1949, p. 11), que havia recebido muitas injeções de morfina, e um manuscrito, que descrevia como "um rapaz inteligente e culto, de excelente família" fora levado aos maiores desatinos por causa da droga, chegando mesmo a ser "acusado do assassinato da mulher, morta em circunstâncias misteriosas". O prefácio serve de moldura para a narrativa contida no manuscrito.

A história de Elza e Helena facilmente poderia ser confundida com o "enredo banal e perpétuo [...] de um casal e uma traição, um amor e uma tragédia" (CAVALCANTI, 1944, p. 31). Alexandre, o autor do manuscrito, apaixona-se por Elza, uma jovem de "olhos imensos e estonteadoramente negros" (CRULS, 1949, p. 15), que lhe é apresentada por seu irmão, Mário. Casam-se, mas o aparente interesse da esposa pelo cunhado e suas mudanças de comportamento abalam a vida conjugal. Tentando salvar seu casamento e preservar a saúde de Elza, o casal vai para a Fazenda Esperança, longe da vida agitada das capitais. Até que Alexandre conhece Helena Davidson. A paixão por Helena leva o rapaz ao vício em morfina e, posteriormente, ao envolvimento na morte da esposa.

A trama, porém, ganha ares sobrenaturais quando o leitor se dá conta de que Elza, a mulher tímida e dócil, e Helena, “irreverente e impetuosa” (CRULS, 1949, p. 148), habitam o mesmo corpo:

Elza era todo um passado de dias amáveis e felicidade terna, lio de sentimentos brandos a congraçarem dois entes que se estimam, corações unidos por uma bem-querença recíproca, ideal da mocidade transubstanciado num amor feito de graça e recato... Helena era o deslumbramento da hora presente, realidade vivida num sonho maravilhoso, miragem ofuscante trazida ao ramerrão da hora que passa; - e a febre dos sentidos, e a ardência da carne, e o brasume dos

4 A saber, Boletim de Ariel, da Ariel Editora, uma das principais revistas da década de 1930, que contava, entre seus colaboradores, com nomes como os de Jorge Amado, Octávio de Faria e Lúcia Miguel Pereira. 
anseios, tudo a crepitar no fogo vivo da luxúria e pronto aos arroubos supremos dos corpos que se agarram e estorcegam, das bocas que se beijam e entredevoram... (CRULS, 1949, p. 156).

\section{O DUPLO COMO DOPPELGÄNGER}

A produção do fantástico pressupõe a existência de dois âmbitos distintos, porém inter-relacionados, e de um limite entre eles. O fantástico surge precisamente quando o limite é ultrapassado, quando um âmbito invade o outro, causando uma perturbação. Essas duas esferas podem se manifestar em oposições diversas: no nível da subjetividade como eu/outro, mas também como vida/morte, vigília/sono, homem/mulher etc. (cf. BRAVO, 1988).

Em Elza e Helena, Gastão Cruls faz uso das “imagens obsedantes" (RANCY, 1982, p. 1) da prosa de ficção decadentista e, em particular, do motivo da duplicidade, recorrente nas narrativas fantásticas, sob a forma de gêmeos, sósias e desdobramentos. Embora seja um tema antigo, ele está presente em narrativas de todas as épocas. Como reconhece Remo Ceserani (2006, p. 83), o duplo fantástico é "fortemente interiorizado", pois está associado à vida da consciência:

[...] o tema, nos textos fantásticos, se torna mais complexo e se enriquece, por meio de uma profunda aplicação dos motivos do retrato, do espelho, das muitas refrações da imagem humana, da duplicação obscura que cada indivíduo joga para trás de si, na sua sombra.

Há muita confusão em relação ao tema da duplicidade. A primeira característica da duplicidade, tal como ela emerge na literatura finissecular, é o fato de que está associada à visão. Não à toa, nessa literatura, o duplo é entendido como Doppelgänger, isto é, como "aquele que vê a si mesmo", num fenômeno de autoscopia, em que o "eu" vê seu alter ego como um objeto visual e, ao mesmo tempo, se sente visto por ele - e igualmente objetificado (cf. WEBBER, 1996, p. 3).

O caso clássico de Doppelgänger é a imagem refletida no espelho. Em "De los espejos", Umberto Eco (2012, posição 215-223) observa que é justamente a "tentação contínua de considerar-me outro" que torna a "experiência especular" singular e inspiradora para a literatura. No romance de Cruls (1949, p. 113), 
Elza vê Helena dominar as suas próprias feições ao sentir a presença da outra e ao fitar-se no espelho:

- Ah, Alexandre, se você soubesse o que aconteceu comigo! Eu não dizia que ela continuava dentro de mim? Imagine que ia escrever à titia e estava já sentada junto da mesinha que fica defronte do psyché, quando, de repente, olhando para o espelho, me vi com uma cara tão diferente, com uns olhos e um sorriso tão esquisitos... Era como se outra pessoa, de sentimentos muito diversos, estivesse animando o meu rosto. A princípio, eu ainda pensei que fosse qualquer efeito de luz ou de posição e, por isso, levantei-me e fui mais perto do espelho. Mas a mudança era mesmo minha e a outra olhava-me sempre com o mesmo ar de desafio, tendo na fisionomia um não sei quê de diabólico e perverso.

Após a publicação, não foram poucos os críticos que observaram a afinidade temática entre o romance de Gastão Cruls e $O$ médico e o monstro: $o$ estranho caso do Dr. Jekyll e Sr. Hyde (1886), de Robert Louis Stevenson. Ambas as histórias retratam "[os] tormentos íntimos, [as] indecifráveis inquietações, [os] angustiosos antagonismos” (SODRÉ, 1940, p. 5) sob a forma do Doppelgänger, tal como aparece na famosa passagem em que Jekyll vê Hyde no espelho após a transformação:

Naquela época, não havia um espelho no gabinete; o que se encontra ao meu lado no momento em que escrevo foi trazido mais tarde, e por causa justamente dessas transformações. Como a noite ia avançada e a manhã, embora muito escura, estivesse prestes a conceber o dia, decidi, inflamado pela esperança e pelo triunfo, mas também sabendo que a criadagem estava ferrada no sono, aventurar-me a ir até meu quarto sob a forma que acabara de assumir. Atravessei o quintal, onde imagino que as constelações tenham observado com pasmo a primeira criatura daquele tipo que até então Ihes havia sido revelada durante sua vigília infatigável. Esgueirei-me pelos corredores, um estranho em minha casa; e, chegando ao quarto, vi pela primeira vez a fisionomia de Edward Hyde (STEVENSON, 2015, posição 1693-1698).

Assim como em O médico e o monstro, o Doppelgänger é usado, em Elza e Helena, para representar um elemento ou traço indesejado da protagonista: o desejo sexual irrestrito. Embora o leitor fique sabendo de início que Sedol, o medicamento para tratar a dor de cabeça de Elza, é o causador da manifestação da outra, a própria Helena conta que suas aparições nada tinham a ver com o remédio, mas sim com o fato de que Elza parecia "ter adquirido, pelo 
menos, até então, maior domínio sobre o corpo em que ambas viviam" (CRULS, 1949 , p. 120). Além disso, Helena faz questão de lembrar a Alexandre que

[...] a não tomasse por uma doença de Elza, um desvario do seu cérebro, uma dissociação da sua consciência, mas como uma criatura real e perfeita, possuidora de um eu próprio, e que, em absoluto, não se podia confundir com a outra (CRULS, 1949, p. 119, grifo do autor).

A sexualidade exacerbada também traz consigo outras características igualmente prejudiciais e até criminosas, como nos lembra Fred Botting (1996, p. 2): o duplo significa “duplicidade e [uma] natureza má”, juntando-se a uma lista crescente de personagens monstruosas, como "cientistas, pais de família, maridos, loucos" no fim do século. Elza pressente a presença de Helena como uma ameaça, mesmo sem saber exatamente do que se tratava:

- Não... Eu não queria dizer... É que desde de manhã, tenho a sensação de sombra que não me deixa. Ainda agora, descendo do barco, tive a impressão nítida de que ela estava juntinho de mim e me ameaçava com a sua mão direita muito aberta, como se me quisesse agarrar pelo pescoço. Houve mesmo um instante em que cheguei a pensar que os seus dedos gelados me tocavam a nuca (CRULS, 1949, p. 101).

A lascívia de Helena também está associada à crueldade, compondo sua natureza fatal e ameaçadora. Durante um passeio, ela e Alexandre se deparam com uma árvore infestada por uma planta parasita, e Helena se mostra impiedosa e cruel ao defender a sobrevivência da planta mais forte:

Lembro-me ainda que, no regresso [do] passeio, em certo trecho da estrada, estaquei o cavalo, para mostrar [a Helena], à beira do caminho, uma árvore, muito minha conhecida, e por cuja sorte nunca deixara de me apiedar, sempre que por ali passava.

Era uma vetusta paineira. Pelo que the restava do tronco harto e da galharia alta, via-se bem que já tivera os seus dias de fausto e majestade. 0 mata-pau, a terrivel e ominosa falsa-parasita, implantara-se, entanto, sobre ela, constringindo-lhe o caule a pouco e pouco, e empecendo-lhe a circulação da seiva. [...] - Não é uma crueldade? - disse eu a Helena. - Tudo isso, que se vê aí, esses troncos e esses galhos, já são da outra, que veio depois e tomou o seu lugar.

Ela, porém, retrucou-me presta:

- Crueldade por quê? Se ela fez isso e pôde vencer, foi só porque era mais forte e inteligente, e tinha portanto todo o direito de viver (CRULS, 1949, p. 144-145).

66 


\section{O DUPLO COMO "RETRATO ASSOMBRADO"}

O segundo caso de duplicidade, o tópos do "retrato assombrado", é um motivo tão importante para o Gótico, que virtualmente nenhum romance Gótico parece estar completo sem um tal caso de identificação errônea com base na "estranha semelhança entre retrato e modelo vivo" (ZIOLKOWSKI, 1977, p. 86). O tema atravessa boa parte da literatura gótica, estando presente desde O castelo de Otranto (1764), de Horace Walpole, chegando a Melmoth, o errante (1820), de Charles Maturin, e às narrativas de fantasmas de meados do século XIX. Nas palavras de Eino Railo, em The haunted castle: a study of the elements of English romanticism (1927):

Desde o início do romantismo terrorífico, [o retrato] exerceu um fascínio particular sobre os autores; para eles, não se tratava de mero objeto inanimado, mas, de algum modo enigmático, de um ser animado, como o quadro de 0 castelo de Otranto (apud ZIOLKOWSKI, 1977, p. 94, nota 26).

No tópos do "retrato assombrado", é o observador que confunde retrato e modelo vivo, o inanimado e o animado, sem que haja necessariamente uma duplicação do tipo Doppelgänger. Além disso, como o próprio nome diz, a duplicidade no "retrato assombrado" se manifesta por meio de um objeto artístico. O exemplo mais conhecido desse tópos é o conto "O retrato oval” (1842), de Edgar Allan Poe, no qual, para o olhar do pintor, o quadro recém-acabado parece mais vivo do que o próprio modelo - a jovem que acaba falecendo após posar para o marido. O tópos é assimilado nos contos de fantasmas da "Gilded Age", a "Era Dourada" da literatura estadunidense, e na prosa de ficção decadentista.

Algumas vezes, o retrato vai ser substituído por outro objeto artístico sem que desapareça a ideia de confusão entre cópia e modelo vivo pelo observador. No romance de Cruls, por exemplo, Helena lança mão de um artifício para que Alexandre possa chamá-la sem aplicar injeções de morfina em Elza. Trata-se de um envoûtement, um feitiço, que utilizaria a boneca de pano de uma melindrosa - na verdade, um enfeite que a própria jovem costurara à sua imagem:

À imitação das outras [bonecas], que enfeitavam o bungalow da Tijuca, Elza esmerara-se na feitura dessa melindrosa (era assim que the chamava), e durante dias e dias passara entretida no seu acabamento. Tudo fora planejado por 
ela, desde o corpo, recortado em flanela rósea e modelado sobre armação de arame e roletes de algodão, até a pintura do rosto, os recamos e atavios da toilette, com pingentes nos lóbulos das orelhas e os pulsos manilhados de braceletes. Elza levara o mesmo capricho a ponto de configurá-la o mais possível à sua própria imagem e, na realidade, a boneca ficara uma Elzazinha muito bem apessoada e parecida com o modelo. Рara isso, preparou-lhe o vestido, que era a cópia exata de um dos dela, e até algumas aparas dos próprios cabelos serviram à composição do monho de ouro que lhe coroava a cabeça (CRULS, 1949, p. 162, grifos do autor).

Como observa Nicole Fernandez Bravo (1996), uma das características mais importantes da duplicidade é seu aspecto parasitário. A pesquisadora recorda que o título original do conto de Edgar Allan Poe é "Life in death", vida na morte. Há uma "continuidade entre o vivo e o inanimado" (BRAVO, 1996, p. 359), e a cópia do modelo se alimenta das "forças vitais do feminino", no que poderia ser considerado um tipo de "assassinato pictórico".

Em Elza e Helena, a medicina se torna incapaz de explicar a existência das duas mulheres num só corpo (cf. CRULS, 1949, p. 79). Na conclusão do romance, após a morte de Elza, Helena aparece para Alexandre, "livre do corpo que não [lhe] pertencia, e era obrigada a arrastar como um fardo", e transforma-se em uma "figura irreal, vulto aplástico e etéreo", perdendo a "realidade tangível da sua presença” (CRULS, 1949, p. 170).

\section{"O ESPELHO"}

Se, no romance Elza e Helena, a duplicidade é mediada por um objeto artístico - a melindrosa costurada pela própria Elza à sua imagem -, os objetos de decoração, em particular os existentes no quarto do casal, testemunham e indicam a presença não de uma, mas de duas mulheres no cômodo. Entre suas lembranças, Alexandre recorda-se de um "grande vaso de Lallique" (CRULS, 1949, p. 41), mas também de um "pequeno fauno", criatura associada ao paganismo, que, "descuidado das horas, brincava sobre a guarnição do relógio de bronze", além do "perfil da Virgem [...] sorrindo na cabeceira do nosso leito". É possível imaginar que o fauno fosse um acréscimo de Helena à decoração com motivos religiosos, associada à devota Elza.

No conto "O espelho" (1938), porém, um casal, sob a influência de um espelho de três faces, decorado com “figurinhas de sátiros e ninfas” (CRULS, 
1951, p. 339), entrega-se a todo tipo de "tentações diabólicas” (CRULS, 1951, p. 342), "volúpias novas, requintes nunca dantes experimentados", bem como ao vício em "álcool e outros estimulantes ainda mais nocivos".

O narrador não nomeado atribui a transformação da esposa, Isa, que "sempre tivera um temperamento muito calmo" (CRULS, 1951, p. 342), em uma "verdadeira bacante, abrasada de desejos, ávida de prazeres e perfeitamente iniciada em todos os segredos da volúpia” (CRULS, 1951, p. 343) à peça decorativa, adquirida num leilão.

O comportamento voluptuoso da esposa e seu cuidado em não proporcionar ao marido "vista fácil sobre o espelho" (CRULS, 1951, p. 345) geram ciúmes e desconfiança no narrador, que teme não satisfazer plenamente "às exigências da carne" (CRULS, 1951, p. 344) e ser traído pelas figuras refletidas no vidro do espelho, que ele não reconhecia como sendo o seu reflexo.

Até que, numa noite, quando Isa se mostrava como nunca "a amante insofrida, a mênade insaciável” (CRULS, 1951, p. 344), a folha central do espelho de três faces se parte de cima a baixo e o narrador vê uma figura congelada: "um animalaço bem arcabouçado, de gorja taurina e peito ancho. E lanzudo como um fauno" (CRULS, 1951, p. 347).

Ao defrontar-se com o "rival viripotente" (CRULS, 1951, p. 347), o narrador mete os pés no espelho para espatifá-lo. Em seguida, arranca a esposa da cama e a arremessa contra o objeto, que se faz em pedaços. Caído sobre Isa e "munido de um estilhaço pontiagudo" (CRULS, 1951, p. 348), ele então abre em seu corpo "profundos e mortais rasgões”. Sob os auspícios do terrível Pã, Isa passa a encarnar aspectos "fora dos nossos moldes, terríve[is], fantástico[s] e doloroso[s]" (BARRETO, 2017, p. 256) da femme fatale finissecular, cujo comportamento contesta os códigos morais da sociedade.

\section{CONSIDERAÇÕES FINAIS}

No presente artigo, procurei mostrar como Gastão Cruls emprega, em sua produção literária, recursos da prosa de ficção decadentista para criar narrativas fantásticas acerca da duplicidade. Publicados poucos anos depois de suas primeiras coletâneas, nas quais encontramos histórias de fantasmas, de vampiros e outros contos "terríveis e fantásticos" (cf. BARRETO, 2017, p. 256), o romance Elza e Helena e o conto "O espelho" terminam de maneira ambígua, 
sem o fechamento narrativo característico da produção literária do século anterior. Como observa Hélio Lopes $(1975$, p. 199) a respeito da produção fantástica brasileira, no artigo "Literatura fantástica no Brasil", o desfecho das histórias "ficou em suspenso" - já que não sabemos o que efetivamente aconteceu a Elza nem temos evidências da transformação testemunhada pelo narrador, aparentemente paranoico, em Isa, sua esposa - e essa é justamente uma das características do "fantástico".

\section{The femme fatale as the double in Gastão Cruls's fiction}

\section{Abstract}

This article aims to examine how Gastão Cruls uses the "obsessive images [images obsédantes]" of the Decadent fiction to create a fantastic narrative about duplicity. Also, I intend to show how Elza e Helena (1927) and "O espelho [The mirror]” (1938) echo the literary tradition of authors like Edgar Allan Poe and Robert Louis Stevenson.

\section{Keywords}

Gastão Cruls. Double. Femme fatale.

\section{REFERÊNCIAS}

BARRETO, L. À margem do "Coivara”, de Gastão Cruls. In: BARRETO, L. Impressões de leitura e outros textos críticos. São Paulo: Companhia das Letras, 2017. p. 253-258.

BONAPARTE, M. The life and works of Edgar Allan Poe: a psycho-analytic interpretation. London: Imago, 1949.

BOTTING, F. Gothic. London, New York: Routledge, 1996.

BRAVO, N. F. Doubles and counterparts. In: BRUNEL, P. (ed.). Companion to literary myths, heroes and archetypes. London: Routledge, 1996. p. 343-382.

BRAVO, V. A. La irrupción y el límite: hacia una reflexión sobre la narrativa fantástica y la naturaleza de la ficción. Ciudad de México: Universidad Nacional Autónoma de México, 1988. 
BROCA, B. Naturalistas, parnasianos e decadistas: vida literária do Realismo ao Pré-modernismo. Campinas: Editora da Unicamp, 1991.

CAVALCANTI, L. Elsa e Elena. Leitura, Rio de Janeiro, p. 31, mar. 1944.

CESERANI, R. O fantástico. Tradução Nilton Cezar Tridapalli. Curitiba: Editora UFPR, 2006.

CRULS, G. Elza e Helena. Romance. São Paulo: Companhia Editora Nacional, 1949.

CRULS, G. O espelho. In: CRULS, G. Contos reunidos. Rio de Janeiro: José Olympio, 1951. p. 339-348.

ECO, U. De los espejos. In: ECO, U. De los espejos y otros ensayos. [S. l.]: Debolsillo, 2012. locais 40-587. Edição do Kindle.

FRANÇA, J. Ecos da pulp era no Brasil: o Gótico e o Decadentismo em Gastão Cruls. Terra roxa e outras terras: Revista de Estudos Literários, Londrina, v. 26, p. 7-17, dez. 2013.

FRANÇA, J.; SILVA, D. A. P. De perseguidas a fatais: personagens femininas, sexo e horror na literatura do medo brasileira. Opiniães: Revista dos Alunos de Literatura Brasileira, São Paulo, v. 5, n. 6-7, p. 51-66, 2015.

GAGNIER, R. The Victorian fin de siècle and Decadence. In: MARCUS, L.; NICHOLLS, P. The Cambridge history of twentieth-Century English literature. Cambridge: Cambridge University Press, 2004. v. 1, p. 30-49.

JOUVE, S. Les décadents. Bréviaire fin de siècle. Paris: Plon, 1989.

LARA, C. de. Literatura fantástica e o Modernismo. O Estado de S. Paulo, São Paulo, n. 150 , p. $10-11,16$ set. 1979 .

LOPES, H. Literatura fantástica no Brasil. Revista Lingua e Literatura, São Paulo, v. 4, p. 185-199, 1975.

OLIVER, M. The bright eyes of Eleonora: Poe's dream of recapturing the impossible. In: OLIVER, M. Upstream. Selected essays. New York: Penguin Press, 2016. p. 61-71. POE, E. A. The philosophy of composition. Graham's Magazine, v. XXVIII, n. 4, p. 163-167, Apr. 1846.

POE, E. A. Tales of mystery and imagination. London: Everyman's Library, 1908.

RANCY, C. Fantastique et décadence en Angleterre: 1890-1914. Paris: Éditions du CNRS, 1982.

RUDDICK, N. The fantastic fiction of the fin de siècle. In: MARSHALL, G. The Cambridge companion to the fin de siècle. Cambridge: Cambridge University Press, 2007. p. 189-206. 
SENNA, H. Lembrança de Gastão Cruls. Correio da Manhã, Rio de Janeiro, p. 8, 20 jun. 1959.

SODRÉ, N. M. Os livros de Cronin. Correio da Manhã, Rio de Janeiro, p. 5, 15 set. 1940.

STEVENSON, R. L. O médico e o monstro: o estranho caso do Dr. Jekyll e Sr. Hyde. Tradução Jorio Dauster. São Paulo: Penguin, Companhia das Letras, 2015. Edição do Kindle.

SYMONS, J. The tell-tale heart: the life and works of Edgar Allan Poe. Middlesex: Penguin Books, 1978.

WEBBER, A. J. The Doppelgänger: double visions in German literature. New York: Oxford University Press, 1996.

WEIR, D. Afterword: decadent taste. In: CONDÉ, A.; DESMARAIS, J. Decadence and the senses. Cambridge: Legenda, 2017. p. 219-228.

ZIOLKOWSKI, T. Disenchanted images: a literary iconology. Princeton: Princeton University Press, 1977. 